\title{
Pattern of Dipyrone Exposure in Texas, 1998 to 2004
}

\author{
Mathias B. Forrester, BS a
}

a Texas Department of State Health Services, Austin, TX

\begin{abstract}
Introduction: Dipyrone is an analgesic and antipyretic agent. The purpose of this study was to describe the pattern of dipyrone exposures reported to poison centers.

Methods: Human dipyrone exposures reported to 6 Texas poison centers from 1998 to 2004 were identified. Isolated and nonisolated cases were compared with respect to various factors.

Results: When compared to the Census, dipyrone exposures were significantly more likely to have been reported from regions closer to the Mexican border (53\% vs 9\%). Of 81 dipyrone exposures, 52 (64\%) were isolated and 29 (36\%) were non-isolated. Most of the dipyrone exposures occurred at the patient's own residence (72/76 or 95\%) and the patients were more likely to be female (54/81 or $67 \%)$. Although the majority of both types of dipyrone exposures were adults (47/78 or $60 \%)$, children, less than 6 years of age, accounted for a higher proportion of isolated exposures (33\% vs 10\%) while a higher proportion of non-isolated exposures involved older children ( $28 \%$ vs $8 \%$ ). Twenty-two percent (11/51) of isolated cases were intentional while 59\% (17/29) of non-isolated cases were intentional. Of those cases with a known medical outcome, the medical outcome was no adverse clinical effect for $76 \%$ $(16 / 21)$ of isolated exposures and $42 \%$ (8/19) of non-isolated exposures. The specific adverse clinical effects reported for isolated exposures were primarily neurological $(n=6)$, gastrointestinal $(n=4)$, and dermal $(n=3)$. The most frequently reported treatment for isolated exposures was some form of decontamination $(n=11)$.

Conclusions: Isolated and non-isolated dipyrone exposures varied with respect to patient age, exposure reason, management site, medical outcome.
\end{abstract}

\section{INTRODUCTION}

Dipyrone (metamizole) is a water soluble pyrazolone nonsteroidal anti-inflamatory agent used as an analgesic and antipyretic. Dipyrone's method of action is inhibition of cyclooxygenase, arachidonic acid-induced platelet aggregation, synthesis of platelet thromboxane, and synthesis of prostaglandins $E_{1}$ and $E_{1}[1-3]$.

Agranulocytosis, a serious and potentially deadly condition involving an insufficient number of the white blood cells neutrophils or granulocytes, has been associated with dipyrone use; although, the rate of agranulocytosis among dipyrone users has demonstrated wide variation between populations. As a result of the association of agranulocytosis with dipyrone, the drug has been banned in the United States, Canada, Japan, and certain countries in Europe. However, dipyrone is still available in Latin American countries (including Mexico), some European countries, Israel, Africa, and Asia [4-6].

In Mexico, dipyrone is available under a variety of names such as Neomelubrina, Magnopirol, Conmel, and Buscapina compositum. It can be obtained over the counter in the form of tablets,

Keywords: dipyrone, poison centers, adverse exposures

Acknowledgments: I would like to thank the staff of the 6 poison centers (Central Texas Poison Center, North Texas Poison Center, Panhandle Poison Center, South Texas Poison Center, Southeast Texas Poison Center, West Texas Regional Poison Center) of the TPCN who collected the data.

Notes: Funding for this research was provided by a contract with the Commission on State Emergency Communications in Texas. Corresponding Author: Mathias B. Forrester, BS, Epidemiology and Disease Surveillance Unit, Texas Department of State Health Services, 1100 W 49th Street, Austin, TX 78756. Email: mathias.forrester@dshs.state.tx.us 
capsules, suspensions, syrup, injections, and suppositories, and dipyrone is available alone or in combination with other drugs in cold/flu preparations, antispasmodics, and vitamins [5-7].

Although dipyrone has been banned in the United States since 1979, the drug may still be bought in Mexico and brought across the border. Moreover, dipyrone-containing products have been found for sale in Latin markets in the United States [8]. As a result, people in the United States may be exposed to a drug with potentially adverse effects with which health care providers in this country may be unfamiliar [7].

There is not much published information from poison centers about the adverse exposures to dipyrone. In Israel, where the drug is legal, one study examined 243 dipyrone exposures [4]. Review of the literature failed to identify any information on dipyrone exposures involving poison centers in the United States, where the drug has been banned for 25 years. The objective of this investigation was to examine the pattern of dipyrone exposures reported to Texas poison centers during a recent seven-year period.

\section{METHODS}

This was a retrospective study using data from the Texas Poison Center Network (TPCN). The TPCN consists of 6 poison centers that collectively service the entire state. All the poison centers use the same Toxicall software and Toxic Exposure Surveillance System (TESS) database to record information on all calls received. The poison centers collect data in a similar manner.

Cases consisted of all human dipyrone exposures reported to the TPCN from 1998 to 2004. The distribution of calls was determined by year, caller location, and number of additional substances involved in the exposure. Caller location was examined in 2 ways: (1) whether the location was in one of the 2 poison centers that border Mexico versus the 4 poison centers that do not and (2) whether the location was within one of the 14 counties that border Mexico versus the 240 counties that do not.

The cases were then grouped into two categories of exposure: (1) isolated (only dipyrone was involved in the exposure) and (2) non-isolated (dipyrone and at least one other substance were involved in the exposure). These categories were chosen because a portion of all dipyrone exposures reported to poison centers might be expected to involve other substances. Thus, poison centers might find information on non-isolated exposures useful. Moreover, it might be expected that the patient characteristics, management of the exposure, and medical outcome might vary depending on the presence or absence of other substances in the exposure. The type and number of other drugs and ethanol involved in dipyrone exposures was described.

The distribution of isolated and non-isolated dipyrone exposures was calculated for patient age and gender, reason and site of exposure, management site, and medical outcome. The groupings for these variables were based on those used in the TESS database. Medical outcome was defined according to the following criteria: no effect (no symptoms due to exposure), minor (some minimally troublesome symptoms), moderate (more pronounced, prolonged symptoms), major (symptoms that are life-threatening or cause significant disability or disfigurement), and death. All of the variables may not have been known for all of the exposures, so the sum for each factor may not equal the total number of human exposures. Patient ethnicity could not be examined because such information is not systematically collected by the TPCN. In 2001, the TPCN began noting which calls were handled in Spanish; however, there is some question whether this information was consistently collected.

The distribution of adverse clinical effects and treatments identified among isolated dipyrone exposures, regardless of the medical outcome (including unknown), was determined. Since adverse clinical effects and treatments were not known for human exposures from 1998 to 1999, these 2 years were excluded from the analysis of clinical effects and treatments.

Differences between types of exposures were analyzed for statistical significance by calculating the rate ratio and 95\% confidence intervals using Poisson probability.

\section{RESULTS}

The TPCN received 229 total calls involving dipyrone from 1998 to 2004. Of these calls, 81 (35.4\%) were human exposures, 69 (30.1\%) drug identifications, and 79 (34.5\%) requests for other information.

The dipyrone exposures demonstrated no clear annual trend during the seven-year period, ranging from 6 to 16 reported exposures per year.

Table 1 presents the distribution of human exposures by caller location. The caller was significantly more likely to be in a poison center bordering Mexico and in a county bordering Mexico.

Of the 81 dipyrone exposures, 52 (64.2\%) were isolated and $29(35.8 \%)$ were non-isolated, involving from 1 to 6 additional substances. Table 2 shows other drugs and ethanol use reported with dipyrone exposures. Other analgesics were reported in $45 \%$ of non-isolated cases. The most frequently reported other drug was, the analgesic, acetaminophen.

Table 3 compares isolated and non-isolated dipyrone exposures with respect to various factors. For both types of exposures, the patients were more likely to be females. Although the majority of isolated and non-isolated dipyrone exposures were adults, a higher proportion of isolated exposures involved children less than 6 years of age while a higher proportion of non-isolated exposures involved older children.

Non-isolated exposures were significantly more likely to be intentional, particularly suspected suicide attempts. Almost all of the dipyrone exposures occurred at the patient's own residence. In the majority of isolated and non-isolated exposures, the patient was already at or en route to a health care facility when the poison center was contacted. However, a higher percentage of isolated dipyrone exposures were managed outside of a health care facility while a higher percentage of non-isolated exposures were referred to a health care facility by the staff of poison centers. 
TABLE 1. Dipyrone exposures reported to the Texas Poison Center Network from 1998 to 2004 by caller location

\begin{tabular}{|c|c|c|c|c|c|}
\hline \multirow[b]{2}{*}{ Caller location } & \multicolumn{2}{|c|}{ Total population 1} & \multicolumn{3}{|c|}{ Human exposures } \\
\hline & No. & $\%$ & No. & $\%$ & $\mathbf{R R}^{2}$ \\
\hline \multicolumn{6}{|l|}{ Poison centers } \\
\hline Bordering Mexico & $5,113,317$ & 24.5 & 55 & 69.6 & $2.84^{3}$ \\
\hline Not bordering Mexico & $15,738,503$ & 75.5 & 24 & 30.4 & $0.40^{3}$ \\
\hline Total known & $20,851,820$ & & 79 & & \\
\hline \multicolumn{6}{|l|}{ Counties } \\
\hline Bordering Mexico & $1,961,542$ & 9.4 & 42 & 53.2 & $5.65^{3}$ \\
\hline Not bordering Mexico & $18,890,278$ & 90.6 & 37 & 46.8 & $0.52^{3}$ \\
\hline Total known & $20,851,820$ & & 79 & & \\
\hline $\begin{array}{l}{ }^{1} \text { According to } 2000 \text { Census } \\
2 \text { Ratio of human exposure } \\
{ }^{3} \text { Statistically significant, i.e. }\end{array}$ & $\begin{array}{l}\text { otal population } \\
6 \text { confidence int }\end{array}$ & oes not & & & \\
\hline
\end{tabular}

TABLE 2. Distribution of human exposures involving dipyrone reported to the Texas Poison Center Network from 1998 to 2004 by the other drugs and ethanol involved in the exposure

\begin{tabular}{|c|c|c|c|}
\hline Substance category & Number & $\begin{array}{l}\% \text { of total } \\
\text { cases }(n=81)\end{array}$ & $\begin{array}{l}\% \text { of non-isolated } \\
\text { cases }(n=29)\end{array}$ \\
\hline Analgesics & 13 & 16.0 & 44.8 \\
\hline Acetaminophen & 5 & 6.2 & 17.2 \\
\hline Ibuprofen & 2 & 2.5 & 6.9 \\
\hline Other analgesics & 6 & 7.4 & 20.7 \\
\hline Anesthetics (lidocaine) & 1 & 1.2 & 3.4 \\
\hline Anticholinergic drugs (butylhyoscine, hyoscine) & 2 & 2.5 & 6.9 \\
\hline Anticoagulants (warfarin) & 1 & 1.2 & 3.4 \\
\hline Antihistamines (cinnarizine, ranitidine) & 2 & 2.5 & 6.9 \\
\hline $\begin{array}{l}\text { Antimicrobials (penicillin, sulfamethoxazole and } \\
\text { trimethoprim, tetracycline) }\end{array}$ & 3 & 3.7 & 10.3 \\
\hline Cold and cough preparations & 1 & 1.2 & 3.4 \\
\hline $\begin{array}{l}\text { Gastrointestinal preparations (lidamidine, } \\
\text { scopolamine, trimebutine) }\end{array}$ & 3 & 3.7 & 10.3 \\
\hline Hormones and hormone antagonists (cyclofenil) & 1 & 1.2 & 3.4 \\
\hline Narcotic antagonists (naloxone) & 1 & 1.2 & 3.4 \\
\hline Vitamins (folic acid, vitamin B12) & 2 & 2.5 & 6.9 \\
\hline Ethanol & 2 & 2.5 & 6.9 \\
\hline Miscellaneous drugs (misoprostol) & 1 & 1.2 & 3.4 \\
\hline Unknown drugs & 4 & 4.9 & 13.8 \\
\hline $\begin{array}{l}\text { A given human exposure might involve multiple substar } \\
\text { Non-isolated cases }=\text { exposures involving dipyrone and }\end{array}$ & $\begin{array}{l}\text { e than one } \\
\text { e other subs }\end{array}$ & & \\
\hline
\end{tabular}


TABLE 3. Distribution of human exposures involving dipyrone reported to the Texas Poison Center Network from 1998 to 2004 by various factors

\begin{tabular}{|c|c|c|c|c|c|c|c|}
\hline \multirow[b]{2}{*}{ Factor } & \multicolumn{2}{|c|}{ All exposures } & \multicolumn{2}{|c|}{ Isolated exposures ${ }^{1}$} & \multicolumn{3}{|c|}{ Non-isolated exposures ${ }^{1}$} \\
\hline & No. & $\%$ & No. & $\%$ & No. & $\%$ & $\mathbf{R R}^{2}$ \\
\hline \multicolumn{8}{|c|}{ Patient gender } \\
\hline Male & 27 & 33.3 & 16 & 30.8 & 11 & 37.9 & 0.81 \\
\hline Female & 54 & 66.7 & 36 & 69.2 & 18 & 62.1 & 1.12 \\
\hline Total known & 81 & & 52 & & 29 & & \\
\hline
\end{tabular}

\section{Patient age (years)}

\begin{tabular}{lrrrrrrr}
$<6$ & 19 & 24.4 & 16 & 32.7 & 3 & 10.3 & 3.16 \\
\hline $6-19$ & 12 & 15.4 & 4 & 8.2 & 8 & 27.6 & 0.30 \\
\hline$\geq 20$ & 47 & 60.3 & 29 & 59.2 & 18 & 62.1 & 0.95 \\
\hline Total known & 78 & & 49 & & 29 & &
\end{tabular}

\section{Exposure reason}

\begin{tabular}{lrrrrrrr} 
Unintentional & 34 & 42.5 & 27 & 52.9 & 7 & 24.1 & 2.19 \\
\hline General & 23 & 28.8 & 20 & 39.2 & 3 & 10.3 & 3.793 \\
\hline Therapeutic error & 7 & 8.8 & 5 & 9.8 & 2 & 6.9 & 1.42 \\
\hline Misuse & 4 & 5.0 & 2 & 3.9 & 2 & 6.9 & 0.57 \\
\hline Intentional & 28 & 35.0 & 11 & 21.6 & 17 & 58.6 & 0.373 \\
\hline Suspected suicide attempts & 21 & 26.3 & 7 & 13.7 & 14 & 48.3 & $0.28^{3}$ \\
\hline Misuse & 3 & 3.8 & 3 & 5.9 & 0 & 0.0 & - \\
\hline Abuse & 1 & 1.3 & 0 & 0.0 & 1 & 3.4 & 0.00 \\
\hline Unknown & 3 & 3.8 & 1 & 2.0 & 2 & 6.9 & 0.28 \\
\hline Adverse drug reaction & 18 & 22.5 & 13 & 25.5 & 5 & 17.2 & 1.48 \\
\hline Total known & 80 & & 51 & & 29 & &
\end{tabular}

\section{Exposure site}

\begin{tabular}{lrrrrrrr} 
Own residence & 72 & 94.7 & 47 & 94.0 & 25 & 96.2 & 0.98 \\
\hline Other residence & 2 & 2.6 & 2 & 4.0 & 0 & 0.0 & - \\
\hline School & 2 & 2.6 & 1 & 2.0 & 1 & 3.8 & 0.52 \\
\hline Total known & 76 & & 50 & & 26 & &
\end{tabular}

\section{Management site}

\begin{tabular}{lrrrrrrr} 
On site (not health care facility) & 21 & 26.3 & 17 & 33.3 & 4 & 13.8 & 2.42 \\
\hline At/en route to health care facility & 52 & 65.0 & 31 & 60.8 & 21 & 72.4 & 0.84 \\
\hline Referred to health care facility & 6 & 7.5 & 2 & 3.9 & 4 & 13.8 & 0.28 \\
\hline Other & 1 & 1.3 & 1 & 2.0 & 0 & 0.0 & - \\
\hline Total known & 80 & & 51 & & 29 & & \\
\hline
\end{tabular}


TABLE 3. (continued)

\begin{tabular}{|c|c|c|c|c|c|c|c|}
\hline \multirow[b]{2}{*}{ Factor } & \multicolumn{2}{|c|}{ All exposures } & \multicolumn{2}{|c|}{ Isolated exposures 1} & \multicolumn{3}{|c|}{ Non-isolated exposures ${ }^{1}$} \\
\hline & No. & $\%$ & No. & $\%$ & No. & $\%$ & $\mathbf{R R}^{2}$ \\
\hline \multicolumn{8}{|c|}{ Medical outcome } \\
\hline No effect & 24 & 60.0 & 16 & 76.2 & 8 & 42.1 & 1.81 \\
\hline Minor effect & 14 & 35.0 & 4 & 19.0 & 10 & 52.6 & 0.36 \\
\hline Moderate effect & 1 & 2.5 & 0 & 0.0 & 1 & 5.3 & 0.00 \\
\hline Major effect & 1 & 2.5 & 1 & 4.8 & 0 & 0.0 & - \\
\hline Death & 0 & 0.0 & 0 & 0.0 & 0 & 0.0 & - \\
\hline Total known & 40 & & 21 & & 19 & & \\
\hline \multicolumn{8}{|c|}{$\begin{array}{l}1 / \text { solated exposures = exposures involving only dipyrone. Non-isolated exposures = exposures involving dipyrone and one or more other } \\
\text { substances } \\
{ }^{2} \text { Ratio of isolated exposure \% to non-isolated exposure \% } \\
3 \text { Statistically significant, i.e., } 95 \% \text { confidence interval does not include } 1.00\end{array}$} \\
\hline
\end{tabular}

The medical outcome was known for $49.4 \%$ (40/81) of all dipyrone exposures $(21 / 52$ or $40.4 \%$ of isolated exposures and $19 / 29$ or $65.5 \%$ of non-isolated exposures). Isolated exposures were twice as likely as non-isolated exposures to have a medical outcome classified as no effect. A higher proportion of nonisolated exposures involved at least minor effects. No deaths were reported with dipyrone exposures.

Table 4 contains the distribution of adverse clinical effects and treatments among the 39 isolated exposures reported from 2000 to 2004. Specific adverse clinical effects were recorded for 12 $(30.8 \%)$ of the cases. The highest proportion of cases had neurological effects, followed by gastrointestinal and dermal effects. The most frequently reported specific adverse clinical effect was vomiting. No specific treatment was listed for the majority of cases. The most frequently reported type of treatment was decontamination, most frequently by administration of charcoal. Treatment other than decontamination was reported in only 5 of the cases.

\section{DISCUSSION}

This study described the pattern of dipyrone exposures reported to Texas poison centers during a recent 7 year period. Although dipyrone has been banned in the United States since 1979, it is available in Mexico and can be brought over the border into the country or even purchased in ethnic markets [4-8]. As a result, people in the United States may be exposed to a drug with potentially adverse effects with which health care providers in the country may be unfamiliar [7]. Thus, information on exposures occurring in the United States might be useful to health care providers.

There were various limitations to this study. The primary limitation is the use of poison center data: reporting adverse exposures to dipyrone to the poison centers is voluntary. Thus data on dipyrone exposures is not likely to be complete and may contain biases. Moreover, the small number of cases limited the ability to identify statistically significant differences. Not examining dosage was another limitation.

Furthermore, no attempt was made to compare the cases within the isolated and non-isolated dipyrone categories by final medical outcome. This was not done because there were only a total of two cases classified as involving moderate or major effects. Cases with minor effects could be grouped with these two cases and the whole group compared to those cases classified as no effect. However, this would assume that those cases with minor effects would substantially differ from those cases with no effect. Moreover, if the analysis of final medical outcome were limited only to isolated or non-isolated dipyrone exposures, then the number of cases in the analyses would be much smaller.

Only $35 \%$ of all calls relating to dipyrone received by Texas poison centers involved actual exposures; the rest were information calls. This might be understandable, considering that dipyrone is banned in the United States and thus may be unfamiliar to those encountering it in this country.

Dipyrone exposures in Texas were substantially more likely to be reported in those areas closer to Mexico. This might be expected because people living closer to Mexico might have greater opportunity to obtain drugs from Mexico. Moreover, the 2000 Census reported that the rates of Hispanics in Texas to be generally higher in areas closer to the Mexican border. Hispanics, particularly those who originated south of the border, might be more inclined to seek out drugs with which they are familiar. Thus regions in the United States that border Mexico might have higher rates of dipyrone use. However, one study reported dipyrone use in Utah [8]. Health care providers in regions hundreds of miles from the Mexican border might have to handle adverse exposures to dipyrone. 
TABLE 4. Adverse clinical effects and treatments among isolated human exposures involving dipyrone $(n=39)$ reported to the Texas Poison Center Network from 2000 to 2004

Number

$\%$ of cases

\section{Adverse clinical effects}

\begin{tabular}{llc} 
Neurological & 6 & 15.4 \\
\hline Agitation & 1 & 2.6 \\
\hline Ataxia & 1 & 2.6 \\
\hline Dizziness & 1 & 2.6 \\
\hline Drowsiness & 2 & 5.1 \\
\hline Seizures & 1 & 2.6 \\
\hline Dermal & 3 & 7.7 \\
\hline Erythema & 1 & 2.6 \\
\hline Hives & 1 & 2.6 \\
\hline Pruritus & 1 & 2.6 \\
\hline Gastrointestinal & 4 & 10.3 \\
\hline Nausea & 1 & 2.6 \\
\hline Vomiting & 3 & 7.7 \\
\hline Other & 1 & 2.6 \\
\hline
\end{tabular}

\section{Treatments}

\begin{tabular}{lcc} 
Decontamination & 11 & 28.2 \\
\hline Cathartic & 4 & 10.3 \\
\hline Charcoal & 8 & 20.5 \\
\hline Food & 3 & 7.7 \\
\hline Lavage & 2 & 5.1 \\
\hline Other & 5 & 12.8 \\
\hline Anticonvulsant & 1 & 2.6 \\
\hline Antiemetic & 1 & 2.6 \\
\hline Antihistamine & 1 & 2.6 \\
\hline Fluids IV & 2 & 5.1 \\
\hline Other & 2 & 5.1 \\
\hline
\end{tabular}

A given exposure might involve multiple adverse clinical effects or treatments Isolated cases = exposures involving only dipyrone.

Thirty-six percent of all reported dipyrone exposures involved other substances. The most frequently reported drugs used in association with dipyrone were analgesics, particularly acetaminophen.

Isolated and non-isolated dipyrone exposures were similar in that the majority of exposures involved female patients and the exposures occurred at the patient's own residence. However, the two types of exposures differed in other aspects. Most of the isolated exposures involved adults, followed by children less than 6 years of age. Although the majority of non-isolated exposures were also among adults, older children were among the next highest proportion. Isolated exposures were most frequently unintentional whereas non-isolated exposures were much more likely to be intentional, particularly suspected suicide attempts. In most instances, of both types of dipyrone exposures, when the patient was already at or en route to a health care facility when the poison center was contacted, a higher proportion of isolated exposures were managed outside of health care facilities. Seventy-six percent of the isolated exposures with known medical outcomes were classified as no effect, with most of the remainder classified as "minor effect." In contrast, over 50\% of non-isolated exposures were classified as "minor effect."

Specific adverse clinical effects were recorded for only $31 \%$ of isolated dipyrone exposures, and only 1 to 3 cases were reported with a specific adverse clinical effect. These adverse clinical effects were most frequently neurological, followed by gastrointestinal and dermal. In several studies, observed adverse reactions to dipyrone are primarily dermal $[9,10]$. Reported treatment was primarily decontamination, most frequently by charcoal.

A previous investigation examined 243 isolated dipyrone exposures reported to a poison center in Israel, where dipyrone is not banned [4]. The current and previous studies are similar in that both found the majority of exposures to involve female patients, to be unintentional, to have occurred at the patient's own residence, to have a medical outcome classified as no effect, and to involve similar adverse clinical effects. Treatment of isolated dipyrone exposures was also similar in the two studies. Any differences between the results of the two studies could be due to chance, differences in the management or recording of cases, differences in the population studied, or the fact that dipyrone was legal in Israel but banned in Texas.

In summary, dipyrone exposures in Texas reported to poison centers were more likely to occur in areas closer to the Mexican border. The majority of exposures involved no other substances. Isolated and non-isolated dipyrone exposures differed with respect to patient age, exposure reason, management site, and medical outcome. Reported isolated dipyrone exposures did not tend to involve serious adverse effects and were treated by decontamination. This information may provide guidance to health care providers who are unfamiliar with this drug. Although banned in the United States, dipyrone is used in the country.

The author has no potential financial conflicts of interest to report.

\section{REFERENCES}

1. Abbate R, Pinto S, Gori AM, Paniccia R, Coppo M, Neri Serneri GG. Activity of dipyrone on intraplatelet arachidonic 
acid metabolism: an in vitro study. Pharmacol Res 1989;

21:43-50.

2. Abbate R, Gori AM, Pinto S, Attanasio M, Paniccia R, Coppo $\mathrm{M}$, et al. Cyclooxygenase and lipoxygenase metabolite synthesis by polymorphonuclear neutrophils: in vitro effect of dipyrone. Prostaglandins Leukot Essent Fatty Acids. 1990; 41:89-93.

3. Frolich JC, Rupp WA, Zapf RM, Badian MJ. The effects of metamizol on prostaglandin synthesis in man. Agents Actions Suppl 1986;19:155-166.

4. Bentur Y, Cohen O. Dipyrone overdose. J Toxicol Clin Toxicol. 2003;42:261-265.

5. Bozzini L, Bunch C. Dipyrone. Micromedex (R) Health Care Series. Greenwood Village, Colorado: Micromedex, Inc. 2000.
6. Lugo AM. Mexican border medications: potential toxicity. J Toxicol Clin Toxicol 1999;37:121-123.

7. Taylor L, Abarca S, Henry B, Friedman L. Use of Neomelubrina, a banned antipyretic drug, in San Diego, California: a survey of patients and providers. West J Med 2001; 175:159-163.

8. Bonkowsky JL, Frazer JK, Buchi KF, Byington CL. Metamizole use by Latino immigrants: a common and potentially harmful home remedy. Pediatrics 2002;109:e98.

9. Anderson JA, Adkinson NF. Allergic reactions to drugs and biologic agents. JAMA 1987;258:2891-2899.

10. Arndt KA, Jick H. Rates of cutaneous reactions to drugs. A report from the Boston Collaborative Drug Surveillance Program. JAMA 1976;235:918-923. 